\title{
EVALUATION OF ENERGY RELEASE RATE FOR MODE 1 CRACK PROPRAGATION IN GLASS/EPOXY COMPOSITE
}

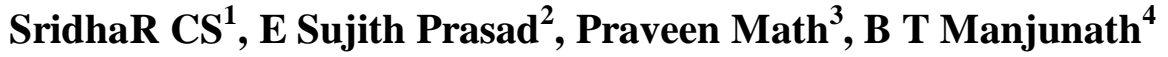 \\ ${ }^{1}$ PG, Student Master of Technology in Machine Design, Department of Mechanical Engineering, T John Institute of \\ Technology, Banglore-560083 \\ ${ }^{2}$ Professor and Head, Department of Mechanical Engineering, T John Institute of Technology, Banglore-560083 \\ ${ }^{3}$ Assistant Professor, Department of Mechanical Engineering, T John Institute of Technology, Banglore-560083 \\ ${ }^{4}$ Associate Professor, Department of Mechanical Engineering, BTL Institute of Technology, Bangalore-560099
}

\begin{abstract}
Composite resources are replacing regular engineering metals along with alloys for several applications. Their superior specific strength and stiffness characteristics have made them very competitive in the aerospace industry. The primary limitation of fiber reinforced composites is fracture toughness, specifically delamination. Delamination failures are common due to the nature of composite construction. A variety of manufacturing techniques are available to make composites. Generally, all these methods employ a layered stacking of fibers in a primary plane. The interface between these layers is typically not reinforced with fibers and is the source of delamination or interlaminar fracture. Porosity and Other manufacturing related defects also introduce nucleation sites for delamination. Methods exist to evaluate and quantify inter-laminar fracture toughness, both experimentally and analytically. The material property that best represents resistance to delamination is the strain energy release rate $\left(G_{C}\right)$. This can be experimentally obtained and numerically predicted with some success. The primary focus of this study was to characterize and address interlaminar fracture in composites. An interlaminar fracture for mode I crack propagation was analysed for GFRP materials having $0^{\circ}$ orientation of fibres. Experimental investigation of $G_{C}$ was done for $40 \%$, 50\% and $60 \%$ of fibre volume. Test was conducted using Double Cantilever Beam specimen. Results obtained were again correlated with Numerical analysis using VCCT method. Results of both experimental and numerical methods were in good agreement.
\end{abstract}

Keywords: S- Glass fiber, Epoxy Resin, Mechanical properties, Hand lay-up. $* * *$

\section{INTRODUCTION}

Composites materials are the combination or mixture of two or more dissimilar materials. That are combined in the macroscopic level but these materials chemically not combined together.

The main aim to develop the composite materials in order to reduce the weight of the materials and improve the mechanical and thermal properties of the components and the structural and the structural applications Composite materials are the combinations of reinforcing, fillers, elements, and matrix binder, differing in form on a macro scale. It should be a strong interface bond between the reinforcement and the matrix is obviously desirable, so the matrix must be capable of developing a mechanical or chemical bond with the reinforcement. The reinforcement and the matrix materials should also be chemically compatible.

In these materials one is matrix material and another is reinforcing material. These depend on the applications and material composition will be changed.. Based on this matrix composite materials are further classified in to metal matrix composites, polymer matrix composites and ceramics.

The structure of polymers consists of long molecules with a backbone of carbon atoms linked by covalent bonds. In noncrystalline or amorphous polymers the molecular chains have an entirely random orientation and are cross-linked occasionally by a few strong covalent bonds and numerous but weaker van der Waals bonds. These weaker bonds break as the temperature reaches a value known as the glass transition temperature, are oriented along preferred directions.

\section{Double Cantilever Beam Specimen}

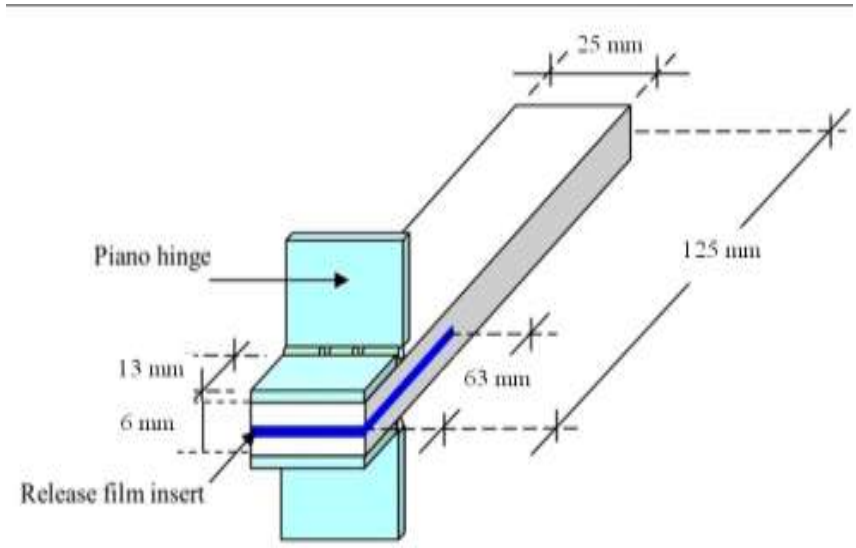

Fig1 DCB specimen

Dimensions of DCB specimen ASTM 5528

Were;

$\mathrm{U}=$ total elastic energy in the test specimen,

$\mathrm{b}=$ width, and

$\mathrm{a}=$ length, 
$\mathrm{l}=125 \mathrm{~mm}$

$\mathrm{L}=63 \mathrm{~mm}$

$\mathrm{a}_{0}=13 \mathrm{~mm}$

$\mathrm{h}=3 \mathrm{~mm}$

$\mathrm{b}=25 \mathrm{~mm}$

The maximum load anticipated during a DCB test of a material with a known a modulus, E11, and anticipated value of GIc, may be estimated by

$$
\mathrm{P}_{\max }=\frac{b}{a} \sqrt{\frac{\mathrm{E}_{11} \mathrm{G}_{\mathrm{IC}} h^{3}}{96}}
$$

Total volume of the specimen $\mathrm{V}=12500 \mathrm{~mm}^{3}=12.5 \mathrm{~cm}^{3}$

Density of S glass $\rho_{\mathrm{g}}=2.45(\mathrm{~g} / \mathrm{cm} 3)$

Mass of $\mathrm{S}$ glass required to prepare specimen with volume fraction, $\mathrm{v}_{\mathrm{f}}=\mathrm{v}_{\mathrm{f}} \mathrm{X} 15 \mathrm{X} 2.45=36.75 \mathrm{v}_{\mathrm{fg}}$

Mass of $\mathrm{S}$ glass used in for fiber volume fraction

Volume fraction $V_{f}=0.4 \quad E_{11}=36$.

Volume fraction $V_{f}=0.4 \quad E_{11}=36.2$

$$
\begin{array}{cc}
V_{f}=0.45 & E_{11}=40.35 \\
V_{f}=0.5 & E_{11}=44.5 \\
V_{f}=0.6 & E_{11}=52.8
\end{array}
$$

\section{Properties of Epoxy Resin}

Density $\rho_{\mathrm{m}}=1.2(\mathrm{~g} / \mathrm{cm} 3)$

Young's Modulus $\mathrm{E}_{\mathrm{m}=} 3$ (Gpa)

Poisson's Ratio $v_{\mathrm{m}}=0.38$

Shear strength $-\tau_{\mathrm{m}}=0.034(\mathrm{Gpa})$

Tensile Strength $-\sigma_{\mathrm{tm}}=0.072(\mathrm{Gpa})$

Axial Compressive strength $\sigma_{\mathrm{mc}}=1.550(\mathrm{Gpa})$

\section{Properties of S-Glass Fiber}

Density $\rho_{\mathrm{g}}=2.45(\mathrm{~g} / \mathrm{cm} 3)$

Young's Modulus $\mathrm{E}_{\mathrm{f}}=86(\mathrm{Gpa})$

Poisson's Ratio $v_{\mathrm{f}}=0.22$

Shear strength $-\tau_{\mathrm{f}}=0.035(\mathrm{Gpa})$

Axial Compressive strength $\sigma_{\mathrm{fc}}=1.550(\mathrm{Gpa})$

From the properties of $\mathrm{S}$ glass and epoxy, based on the their volume fraction elastic moduli are obtained.

From the properties of S glass and epoxy, based on the their volume fraction elastic moduli are obtained
a. Longitudinal young's modulus, $\mathrm{E}_{1}=\mathrm{E}_{\mathrm{f}} \mathrm{V}_{\mathrm{f}}+\mathrm{E}_{\mathrm{m}} \mathrm{V}_{\mathrm{m}}$
b. Major Poisson's ratio,

$$
{ }_{12}={ }_{\mathrm{f}} \mathrm{V}_{\mathrm{f}}+{ }^{0}{ }_{\mathrm{m}} \mathrm{V}_{\mathrm{m}}
$$

The study was performed for $0^{\circ}$ orientation of glass fiber having 9 elastic constants in numerical method.

$$
\begin{gathered}
E_{11}=V_{f}+E_{f 11}+V_{m} E_{m} \\
E_{22}=E_{33}=\frac{\mathrm{E}_{\mathrm{f} 22} \mathrm{E}_{\mathrm{m}}}{E_{f 22} V_{m}+E_{m} V_{f}} \\
G_{12}=G_{13}=\frac{\mathrm{G}_{\mathrm{f} 12} \mathrm{G}_{\mathrm{m}}}{G_{f 12} V_{m}+G_{m} V_{f}}
\end{gathered}
$$

$$
\begin{gathered}
G_{23}=\frac{\mathrm{G}_{\mathrm{f} 23} \mathrm{G}_{\mathrm{m}}}{G_{f 12} V_{m}+G_{m} V_{f}} \\
v_{12}=v_{13}=V_{f} v_{f 12}+V_{m} v_{m} \\
v_{23}=V_{f} v_{f 23}+V_{m} v_{m}
\end{gathered}
$$

\section{FABRICATION AND TESTING}

1. The fabrication of the polymer matrix combined was prepared at extent temperature.

2. Prepare the mould cavity according to the specimen dimensions.

3. Fibers are chopped in uni directional and placed on the mould cavity.

4. The epoxy and resins mixed together and applied on the fibers in layer by layer.

5. PTFE is used as the releasing agent, load is kept on the cavity for he certain interval of time.

Testing Procedure

1. Measure the width and thickness of each specimen to the nearest at the midpoint and from either end.

2. Coat both edges of the specimen just ahead to identify the crack length..

3. The specimen is fixed in between the two hinges, aligned center to the specimen.

4. Once load gets increased the crack starts propagating gradually. Reading should be note down.

5. As the load increases the specimen breaks at that point.

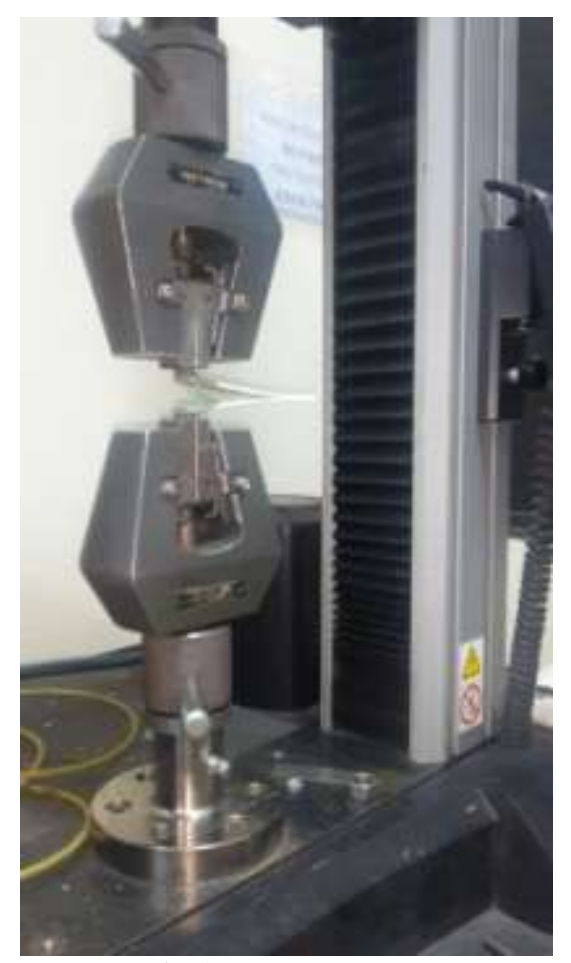

Fig 2 UTM machine

Machine Make: Instron

Model:5569

Capacity:50KN

Universal Testing Machine 


\section{RESULTS AND DISCUSSIONS}

Numerical results and Experimental results are compared to plot the graph. Numerical method is done by Virtual Crack Closure Technique and compared both results.

\subsection{Numerical Analysis of Double Cantilever Beam} for different volume fraction of Fiber

\subsubsection{Fiber Volume Fraction $V_{\mathrm{f}}=0.4$}
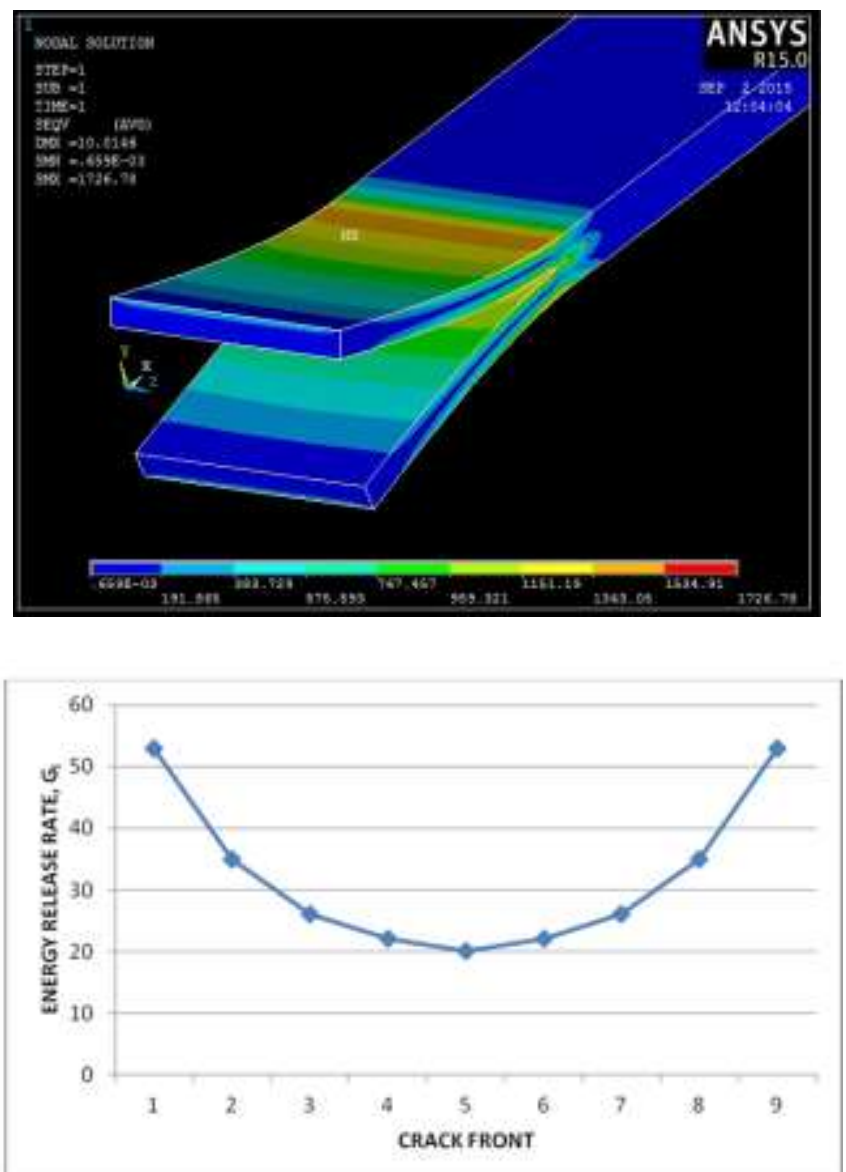

Fig 3: Graph gives the pattern of $\mathrm{G}$ value along the crack front. Around $51.2 \mathrm{~J} / \mathrm{m}^{2}$.

\subsubsection{Fiber Volume Fraction $V_{f}=0.45$}

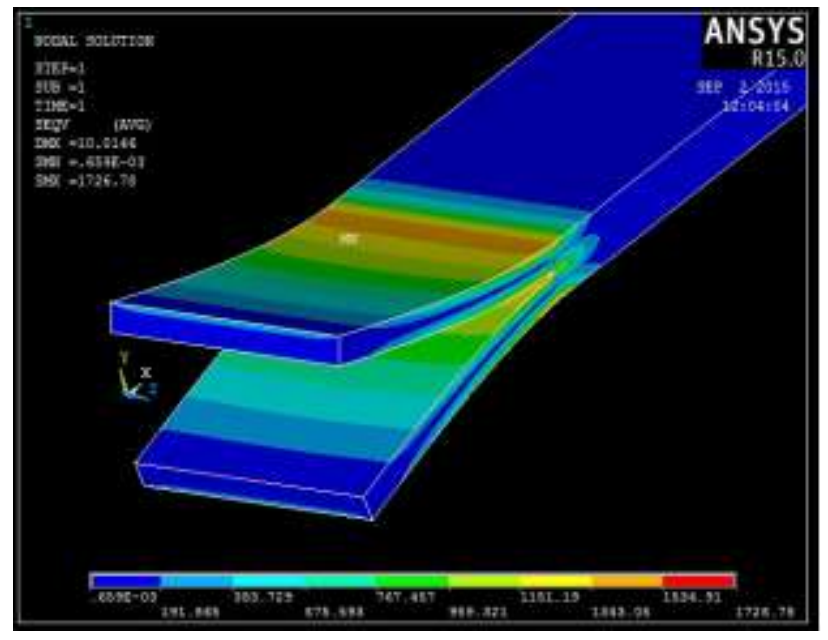

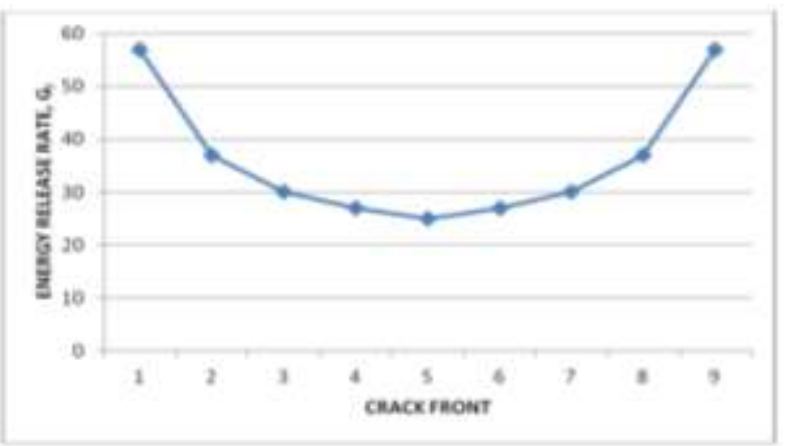

Fig 4: Graph gives the pattern of $G$ value along the crack front. Around $56.6 \mathrm{~J} / \mathrm{m}^{2}$.

\subsubsection{Fiber Volume Fraction $V_{f}=0.5$}
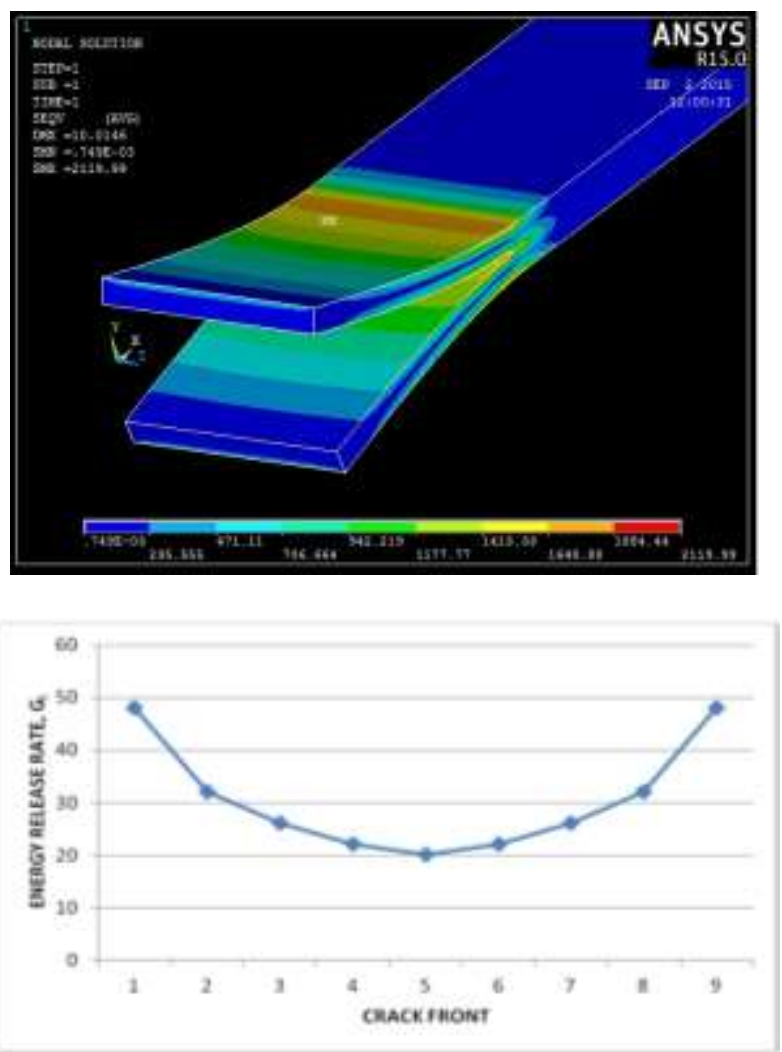

Fig 5: Graph gives the pattern of $G$ value along the crack front. Around $47.4 \mathrm{~J} / \mathrm{m}^{2}$

\subsubsection{Fiber Volume Fraction $V_{f}=0.6$}

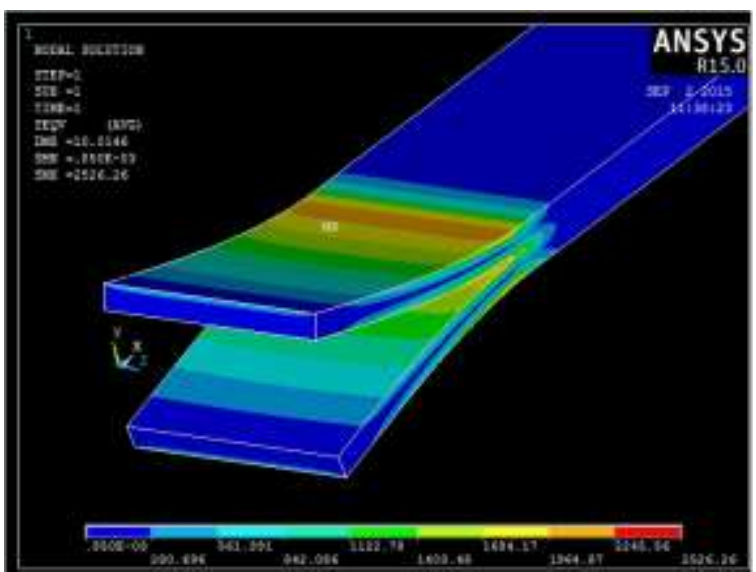




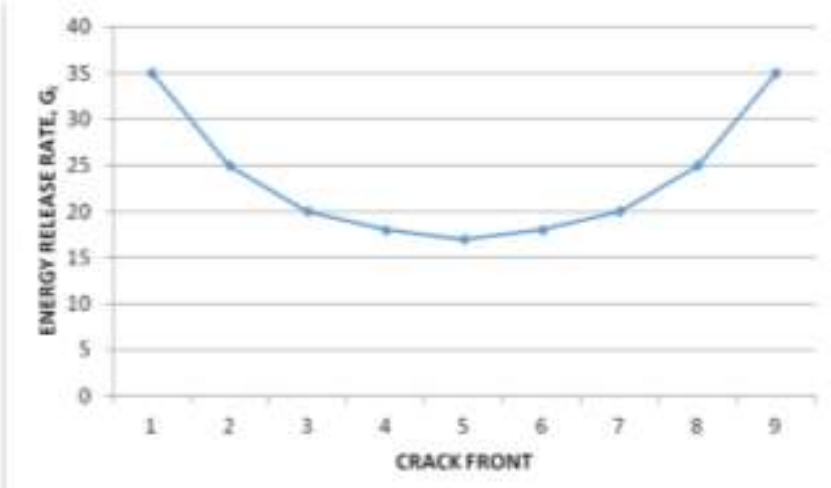

Fig 6: Graph gives the pattern of $\mathrm{G}$ value along the crack front. Around $35.1 \mathrm{~J} / \mathrm{m}^{2}$.

3.2 Experimental Results Calculated using above Mentioned Formulas

\subsubsection{Fiber Volume Fraction $V_{f}=0.4$}

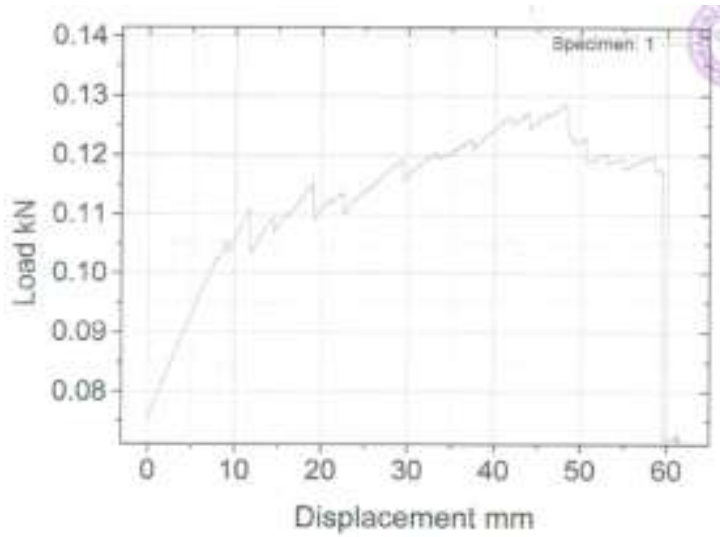

Fig 7

$$
G_{1 c}=96 \frac{P \operatorname{maxa} a^{2}}{E_{11} h^{3} b^{2}} G_{1 c}=53.64 \mathrm{~J} / \mathrm{m}^{2}
$$

\subsubsection{Fiber Volume Fraction $V_{f}=\mathbf{0 . 4 5}$}

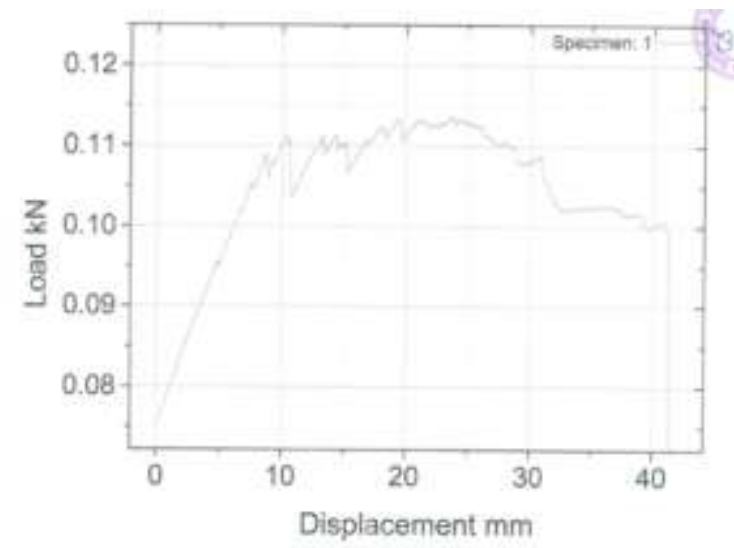

Fig 8

$$
G_{1 c}=57.07 \mathrm{~J} / \mathrm{m}^{2}
$$

\subsubsection{Fiber Volume Fraction $V_{f}=0.5$}

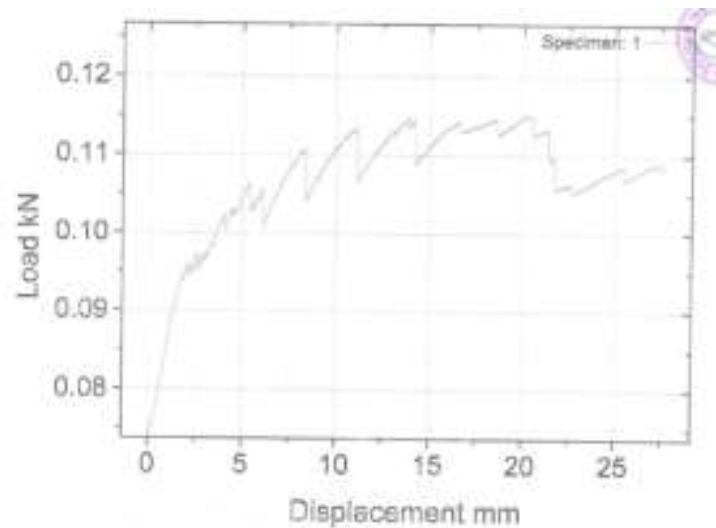

Fig 9

$$
G_{1 c}=48.71 \mathrm{~J} / \mathrm{m}^{2}
$$

\subsubsection{Fiber Volume Fraction $V_{\mathrm{f}}=0.6$}

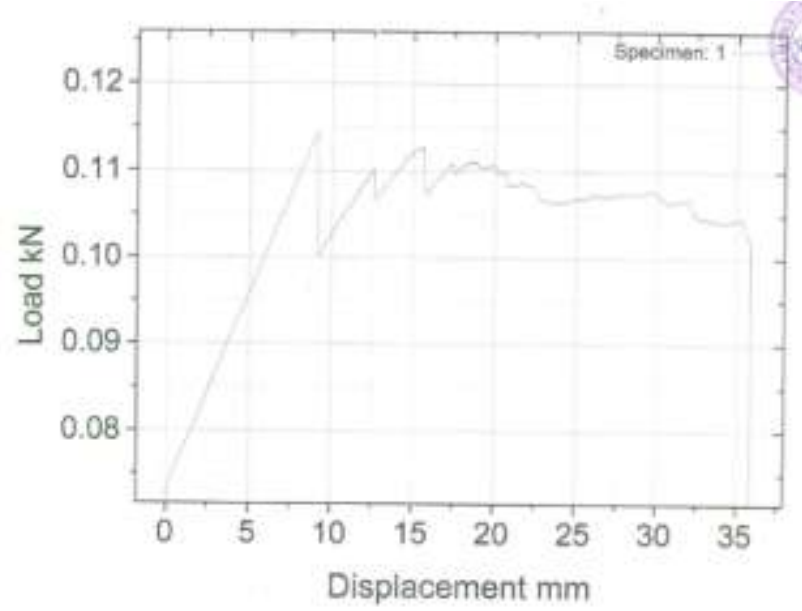

Fig 10

$$
G_{1 c}=34.21 \mathrm{~J} / \mathrm{m}^{2}
$$

\subsection{Comparison of Numerical Results with}

\section{Experimental Results}

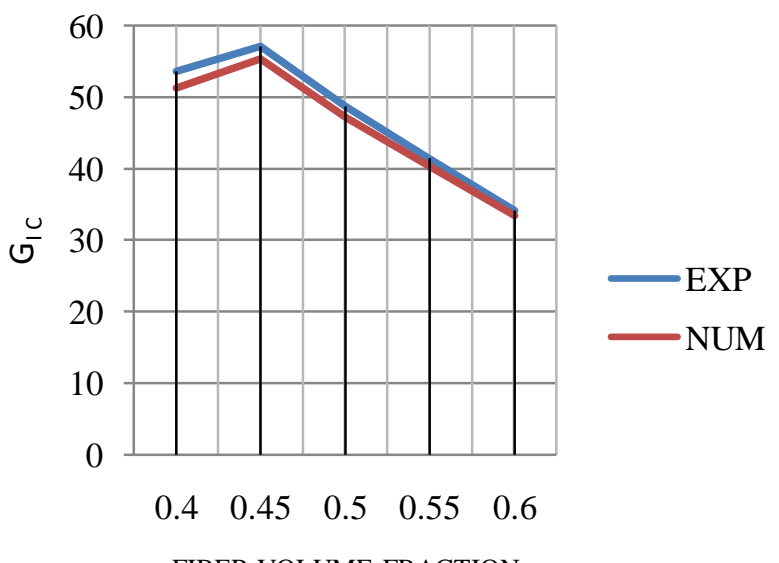

FIBER VOLUME FRACTION

Fig 11 comparison graph 


\section{CONCLUSION}

1. An wide-ranging analysis for Mode I has been performed in arrange to revise the model of Energy Release rate deviation with admiration to modify in fiber volume throughout numerical method and also for the same fiber volume fraction experimental methodology is done.

2. The revise was performed for $0^{\circ}$ orientation of glass fiber having 9 elastic constants in numerical method.

3. The fibers are hand lapped and specimen is prepared for experimental method. It clear shows at $45 \%$ fiber the energy release rate will be more both in numerical and experimental in mode I.

4. The results obtained so far are quite satisfactory. The experimental and numerical results were compared and found almost similar.

5. Hence it is clear from both numerical and experimental as percentage of fiber increase Energy release rate decreases in Mode I.

\section{REFERENCES}

[1]. J.R. Eisenmann, B.E. Kaminski, Fracture control for compositestructures ,Engineering Fracture Mechanics, Volume 4, Issue 4, December 1972, Pages 907-913

[2]. StefanosGiannis, Utilizing fracture mechanics principles for predicting the mixed-mode delamination onset and growth in tapered composite laminates, Composite Structures, Volume 102, August 2013, Pages 294-305

[3]. A. Salvadori, P. A. Wawrzynek,A. R. Ingraffea Energy dissipation in the mixed mode growth of cracks at the interface between brittle materials, International Journal of Fracture, June 2013, Volume 181, Issue 2, pp 257-271.

[4]. Gianpietro Del Piero, AVariational Approach to Fracture and Other Inelastic Phenomena, Journal of Elasticity June 2013, Volume 112, Issue 1, pp 3-77

[6]. Xiang Qiao Yan, Du Shanyi, Wang Duo, J-Integral criterion of delamination onset in toughened matrix composite laminates,Engineering Fracture Mechanics, Volume 40, Issue 1, 1991, Pages 67-74

[7]. Ye Zhu, Characterization of inter laminar fracture toughness of a Carbon/Epoxy composite material in Engineering mechanics 2009

[8]. J. Brillaud, A. El Mahi, Numerical simulation of the influence of stacking sequence on transverse ply cracking in composite laminates, Composite Structures, Volume 17, Issue 1, 1991, Pages 23-35

[10]. Barry D. Fehla, Kevin Z. TrumanbAn evaluation of fracture mechanics quarter-point displacement techniques used for computing stress intensity factors, Engineering Structures, Volume 21, Issue 5, May 1999, Pages 406-415 [11]. ASTM standard D5528-01. Standard Test Method for Mode I Interlaminar Fracture toughness of Unidirectional Fiber-Reinforced Polymer Matrix Composites. American Society for Testing and Materials, USA (2002) 